\title{
ENTRE A REIFICAÇÃO DA ARQUITETURA MODERNISTA E 0 APAGAMENTO DA MEMÓRIA: O CASO DE CATAGUASES - MG
}

\section{BETWEEN APPRECIATION OF THE MODERNIST ARCHITECTURE AND MEMORY ERASURE: THE CASE OF CATAGUASES - MG}

\author{
Danilo Celso Pereira ${ }^{1}$ \\ Instituto do Patrimônio Histórico e Artístico Nacional, Brasília, Distrito Federal, Brasil, danilo.paraitinga@gmail.com
}

\begin{abstract}
Resumo
Excluída da "civilização do ouro" de Minas Gerais, Cataguases teve sua colonização do começo do século XIX ligada à agropecuária e à cafeicultura. No início do século XX recebeu algumas indústrias, destacando-se no ramo têxtil e metalúrgico, acarretando seu desenvolvimento. Explica-se daí uma série de monumentos recentes assinados por alguns dos mais importantes artistas do modernismo, o que permite aos moradores de Cataguases falarem de um "movimento modernista" da cidade, contudo, seu espaço urbano apresenta uma riqueza de tipologias arquitetônicas com bens neocoloniais, ecléticos e art déco. Apesar disso, apenas o modernismo é exaltado como de relevância, tanto pelas instituições locais, como pelo Instituto do Patrimônio Histórico e Artístico Nacional (Iphan) que tombou a cidade em 1994. Assim, pretende-se nesse texto problematizar questões referentes ao processo de seleção do conjunto urbano de Cataguases como patrimônio cultural nacional, com destaque para a delimitação do perímetro de tombamento que se deu, sobretudo, pela valoração arquitetônica em detrimento da salvaguarda da memória dos grupos sociais que habitam a cidade, em particular a memória operária.
\end{abstract}

Palavras-chave: Patrimônio cultural. Políticas de preservação. Memória. Cataguases. Iphan.

\begin{abstract}
Deleted from the "gold civilization", Cataguases had his colonization in the early nineteenth century linked to agriculture and coffee growing. In the twentieth century, it received some industries, especially the textile and metal industry, encouraging its development. This explains a number of recent monuments, signed by some of the most important artists of modernism, which allows residents of Cataguases speak of a "modernist movement "of the city, yet its urban space presents a wealth of architectural typologies neo-colonial, eclectic and art deco. However, only the modernist architecture is exalted as much relevance by local institutions and by the National Institute of Historic and Artistic Heritage, responsible for the preservation of this urban area since 1994. Thus, it is intended in this text discuss issues relating to listing the urban area preservation the Cataguases as national cultural heritage, especially the delimitation of perimeter protection that occurred mainly by architectural valuation at the expense of safeguarding the memory of groups social inhabiting the city, in particular, the working memory.
\end{abstract}

Keywords: Cultural heritage. Preservation policies. Memory. Cataguases. Iphan.

\section{How to cite this article:}

PEREIRA, Danilo Celso. Entre a reificação da arquitetura modernista e o apagamento da memória: o caso de Cataguases - MG. PARC Pesquisa em Arquitetura e Construção, Campinas, SP, v. 7, n. 1, p. 46-57, mar. 2016. ISSN 1980-6809. Disponível em: <http://periodicos.sbu.unicamp.br/ojs/index.php/parc/article/view/8644408>. Acesso em: 12 ago. 2016. doi:http://dx.doi.org/10.20396/parc.v7i1.8644408. 


\section{Introdução}

O tombamento federal de Cataguases desempenhou um importante papel simbólico por se constituir na eleição da primeira cidade-patrimônio que não representava o período colonial e nem a arquitetura barroca no estado de Minas Gerais, além de ter quebrado um hiato de 56 anos sem tombamentos de cidades no estado, visto que as ultimas ações nesse sentido foram a dos pioneiros fundadores do Instituto do Patrimônio Histórico e Artístico Nacional (Iphan) ${ }^{1}$ em 1938. Assim, pretende-se nesse texto problematizar questões referentes ao processo de seleção da cidade de Cataguases como patrimônio cultural a partir de uma análise do contexto nacional de preservação federal, com destaque para a delimitação do perímetro de tombamento que se deu, sobretudo, pela valoração arquitetônica em detrimento da salvaguarda da memória dos grupos sociais que habitam essa cidade.

Cataguases destacou-se no cenário nacional no século XX por uma intensa produção cultural ligada ao cinema, à literatura e à arquitetura modernista. Contudo, o principal fator que possibilitou essa efervescência cultural em um povoado fundado em 1828, através de uma campanha do Império de explorar os territórios ainda não ocupados em Minas Gerais por meio da exploração cafeeira, foi a chegada da estrada de ferro Leopoldina Railway Company em 1877, transformando a vila em um importante ponto de embarque/desembarque e de exportação de café na região, estabelecendo importante vínculo comercial com a então capital do país, o Rio de Janeiro. A partir de 1905, em decorrência da riqueza acumulada pela produção e comercialização do café, Cataguases começa a vivenciar um novo processo social, a industrialização, que acarretou profundas transformações no seu espaço urbano.

\section{A construção de um patrimônio cultural nacional}

No Brasil, como destacou Fonseca (2009), desde o século XVIII foram encontradas referências sobre iniciativas visando à salvaguarda do patrimônio, contudo, apenas em 1933 surgiu a primeira lei federal referente a essa temática, o Decreto $\mathrm{n}^{\mathrm{o}} 22.298$, de julho de 1933, que elevou a também cidade mineira de Ouro Preto à categoria de Monumento Nacional com a justificativa de este ser o lugar da formação da nacionalidade brasileira, além da presença de diversas obras de arte:

Considerando que a cidade de Ouro Preto, antiga capital de Minas Gerais, foi palco de acontecimentos de alto relevo histórico na formação da nossa nacionalidade e que possui velhos monumentos, edifícios e templos de arquitetura colonial, verdadeiras obras de arte, que merecem defesa e conservação. (BRASIL, 1933)
Para Sant'Anna (1995), a declaração de Ouro Preto como Monumento Nacional, embora de caráter assistemático e pontual, marcou o início da cidade mineira como cidadeparadigma da nacionalidade, berço da cultura brasileira e obra de arte a ser conservada em sua total integridade.

Contudo, foi o Decreto-lei 25, de novembro de 1937, a primeira lei brasileira específica referente à preservação do patrimônio, quando se organizou a salvaguarda dos bens culturais através do tombamento.

Nesse contexto, Getúlio Vargas, apoiado pelos intelectuais modernistas, criou em 1937 o Iphan, órgão que passou a replicar o modelo de preservação do patrimônio adotado em Ouro Preto, a cidade "obra de arte", para as outras cidades do Brasil até fim os anos 1970.

Durante esses primeiros 40 anos de atuação do Iphan, os critérios de seleção, autenticidade e restauração dos bens eram sustentados basicamente na autoridade e no notório saber dos intelectuais integrantes da instituição. $\mathrm{O}$ valor estético do bem, que era atribuído conforme a visão dos arquitetos modernistas, que constituíam a maioria dos funcionários do Iphan, predominou sobre todos os outros no trabalho de construção do patrimônio histórico e artístico nacional. Assim, a avaliação do valor histórico ficava em segundo plano, restrito à vinculação do bem aos fatos memoráveis da história do Brasil (FONSECA, 2009).

Logo, no que se refere à salvaguarda de conjuntos urbanos, o tratamento metodológico adotado na instrução dos processos de tombamento identificava as representações do espaço como monumentos, as cidades-monumentos. Sant'Anna (1995, p. 137) aponta que:

Essa identificação, além de remeter a uma preservação global do objeto urbano, implicou também a sua apreensão como obra de arte, objeto de época ou um todo fechado, cuja expansão ou modificação jamais poderia ocorrer em seu próprio âmbito, mas somente fora dele e bastante afastado. A expressão cidade-monumento, correntemente utilizada na época, indica esplendidamente essa aproximação que, além de fundamentar a abordagem mais propriamente urbanística do problema, também teve importantes reflexos nas regras que foram montadas nessa época para a aceitação de construções novas nessas áreas.

Na prática, a cidade concebida como monumento consistia na supervalorização do componente estético, era a cidade concebida enquanto obra de arte, resultando em um descaso aos seus componentes sociais e econômicos, o que repercutia nos usos e atividades desenvolvidas nessas cidades e nas possibilidades reais de conservação. Essa concepção de cidade-monumento "possibilitou a construção de um quadro conceitual e metodológico para o desenvolvimento de ações que até hoje marcam 
profundamente a instituição" (SANT'ANNA, 1995, p. 117).

Motta (2000) destacou ainda que o acervo selecionado com base em critérios estético-estilísticos e de excepcionalidade como patrimônio nacional, assimilado como natural, formou um quadro social da memória e incorporou-se à memória social, circunscrevendo as ações dos períodos subsequentes, mesmo que baseados em propostas diferentes.

Deste modo, para a autora:

\section{[...] a imagem da nação foi apropriada como ideia lato sensu, ficando esquecidas a origem e os motivos da escolha dos imóveis e sítios coloniais elou excepcionais como patrimônio. Não houve consciência de que este patrimônio era um determinado recorte feito sobre a produção brasileira em acordo com um projeto e momento histórico específico, levando ao uso de critérios semelhantes de seleção do patrimônio cultural, observando-se aspectos estético-estilísticos e a excepcionalidade, em contextos históricos diferentes e diante de novos projetos de identidade cultural. (MOTTA, 2000, p. 31)}

Assim, o sentido inicial dos trabalhos do Iphan na construção da noção de patrimônio no Brasil repercute na sua atuação até hoje, vigorando a imagem de um patrimônio excepcional. Ou seja, de acordo com Sant'Anna (1995) e Motta (2000), a ênfase no valor artístico segundo o gosto educado dos arquitetos, as referências na história dos estilos, a ideia de uniformidade, à semelhança do que foi selecionado como objeto da memória nacional nos seus primeiros anos de atuação, passou a identificar o valor de patrimônio, tornando-se padrão exigido na seleção dos objetos culturais para preservação, não considerando outros valores culturais que os objetos pudessem conter. Trata-se de um status de patrimônio incorporado à memória, correspondente a uma imagem a qual outros valores de caráter histórico, cultural, afetivo e cognitivo não tiveram força para se somar.

A partir da década de 1970 a valoração das cidadespatrimônio começou a passar por algumas mudanças. $\mathrm{O}$ Iphan reconheceu a necessidade de abranger um acervo mais numeroso de cidades, em vista do entendimento de que o valor patrimonial também poderia servir ao desenvolvimento do turismo e da promoção do desenvolvimento das cidades, que não mais poderiam ser tratadas apenas como obras de arte finita. Assim, passouse a admitir uma dinâmica desses bens, considerada improvável anteriormente, e a sua percepção a partir de diferentes fases de desenvolvimento fundamentando a perspectiva histórica e o seu desenvolvimento como objeto socialmente construído em permanente transformação e não limitada às suas qualidades artísticas, acabadas, prontas ou finitas, conforme desenvolvidas até então (MOTTA, 2000).

Contudo, foi a partir dos anos 1980 que se iniciou de fato um processo de revisão crítica dos procedimentos de instrução dos tombamentos e dos critérios de seleção, quando passou a reivindicando-se maior transparência e legitimidade científica aos processos de valoração dos bens culturais. Para Sant'Anna (1995), esse momento marcou a crise da avaliação puramente estética e arquitetônica das cidades-patrimônio, em favor de uma abordagem mais ampla.

Desta forma, nesse momento a grande mudança na prática de seleção se referiu aos critérios estéticos que foram deixados de lado, e parte significativa dos tombamentos passaram a ser fundamentados pelos valores históricos dos bens. Assim, ocorreu uma mudança de conceito, a cidadepatrimônio passou a ser concebida como um "documento histórico, um objeto cultural vinculado também à história, à etnografia, à arqueologia, ao urbanismo e a outras disciplinas, além da história da arte e da arquitetura, como era usual" (SANT'ANNA, 1995, p. 215), temos então, a cidade-documento.

Assim, agora as cidades-patrimônio não se constituíam mais como obra de arte, mas sim "como um documento que informa sobre a ocupação do território brasileiro e sobre os processos históricos de produção do espaço" (SANT'ANNA, 1995, p. 218). Assim, teve-se pela primeira vez o tombamento de áreas consideradas sem valor artístico, mas que representavam situações sociais e econômicas que marcaram a evolução das cidades no Brasil.

Ainda nesse sentido, Motta (2000, p. 108) destacou que essas cidades representavam:

\section{[...] um marco da conquista do território brasileiro. Mas o quê desse território ocupado? A sua relação com o sítio natural que resulta de um complexo de elementos que representam materialmente processos de organização e evolução de uma cidade. Não se tratava da preservação da soma de valores individuais, mas dos vestígios do processo de ocupação e permanência do homem ocidental naquele lugar.}

Não obstante, nos anos 1990 o Iphan se mostrou incapaz de manter os avanços conquistados na década anterior, sucumbindo novamente à seleção de bens culturais pelo gosto dos arquitetos. Tais práticas de seleção até se acentuaram com a exacerbação dos valores ditados pelo neoliberalismo, o capital e o lucro, inserindo não só as cidades-patrimônio, mas a maioria das cidades brasileiras em um espaço de disputas do mercado global. Desta forma, se fortaleceu a apropriação do patrimônio como mercadoria, empregando critérios para sua transformação em produto, visando o consumo visual, guiados por 
padrões de beleza ditados pelo mercado. Conforme Motta (2000, p. 17), no dia " 15 de março de 1990, quando mudou o governo federal, iniciou-se a implantação da política de apropriação do patrimônio para o mercado de consumo".

Contudo, como apontou Chuva (2013), no que se refere aos discursos de valoração nos anos 1990, é necessário considerar que os técnicos não tinham uma posição única, as tensões e posições antagônicas eram constantes. Os processos de tombamento refletem esse fato. Assim, mesmo havendo o conceito de cidade-documento, que predominou na instrução dos processos de tombamento em certo momento, ele não foi homogêneo, ele conquistou apenas parte dos técnicos. Esses técnicos foram superados, mas não houve o retorno à cidade-monumento, não se ignorou completamente a história da ocupação do território, talvez o que seja significativo, mas os valores estéticos voltaram a predominar (informação verbal) ${ }^{2}$.

É nesse contexto, entre o final dos anos 1980 quando se buscavam novos caminhos para a seleção das cidadespatrimônio, e o início dos anos 1990 com o retorno dos critérios baseada na história da arquitetura e nos seus valores estético-estilísticos, que se deram as ações do Iphan em Cataguases.

Assim, em 1987, a partir de uma demanda local, quando a Secretaria Municipal de Cultura solicitou ao Iphan uma parceria que tinha como objetivo levantar dados visando o resgate da cultura e da memória cataguasense, evidenciando o movimento modernista ocorrido na cidade na década de 1920, iniciaram-se as ações do instituto no município.

Em parceria com a Prefeitura Municipal de Cataguases, com a Faculdade de Filosofia, Ciências e Letras de Cataguases (FAFIC) e a Superintendência do Iphan de Minas Gerais, se desenvolveu o projeto "Memória e Patrimônio Cultural de Cataguases". O presente projeto tinha como objetivo desenvolver um trabalho de divulgação e valorização das manifestações culturais da cidade, promovendo a preservação a partir da conscientização da população através do reconhecimento da importância das suas manifestações culturais. À época não se objetivava tombamentos, a não ser que a partir desse projeto essa demanda surgisse na comunidade, concatenado, assim, com os novos preceitos de seleção de bens culturais dos anos 1980, como foi exposto.

O projeto se deteve ao movimento modernista dos "Verdes", um grupo de jovens literatos moradores da cidade que publicam a Revista Verde entre 1927 e 1929, de cunho modernista e que alcançou repercussão nacional. Para o Iphan (1994, p. 07):

A repercussão do fenômeno Cataguases deu-se principalmente em função da origem da revista Verde, pois a realização desta publicação da Mata ofereceu ao país uma resposta positiva sobre a viabilidade da produção cultural em regiões excluídas dos centros polarizadores de informação [...]. Foi a tradução provinciana de um esforço de autossuperação cultural.

Desta forma, este grupo teria sido o responsável por abrir caminho para outras manifestações culturais na cidade, que viriam a ocorrer a partir de então.

Já em 1994, no contexto da volta da seleção das cidadespatrimônio ditada pelos valores estético-estilísticos, a parceria se ampliou com a participação do Instituto de Arquitetos do Brasil (IAB) e o Instituto Estadual do Patrimônio Histórico e Artístico de Minas Gerais (IEPHA), resultando na publicação "Cataguases - um olhar sobre a modernidade", focado em arquitetura, artes plásticas, mobiliário, cinema e literatura produzidos na cidade. Para Alonso (2010, p. 34):

\section{Pode-se dizer que aquela publicação foi uma das primeiras análises detalhadas daquelas manifestações culturais de Cataguases e foi muito utilizado para o embasamento técnico do dossiê de tombamento que seria feito naquele mesmo ano de 1994.}

Assim, essa última publicação marcou o momento de ruptura entre os trabalhos até então realizados, voltado aos inventários participativos, para uma ação voltada ao patrimônio material edificado. Aqui cabe ressaltar que a solicitação de tombamento foi feita pela então superintendente do Iphan em Minas Gerais, Claudia Lage, ao então presidente do Iphan, Glauco Campello, se constituindo de uma ação "de cima para baixo", no sentido de que não foi necessário o surgimento de uma demanda local de acautelamento como se havia proposto em 1987.

Os estudos voltam-se, a partir de então, à produção arquitetônica modernista da cidade, produção essa que se iniciou nos anos 1940 e estendeu-se até o fim da década de 1960. O marco inicial dessa produção foi a construção da residência Francisco Inácio Peixoto, projetada em 1941 por Oscar Niemeyer, com jardins de Burle Marx, esculturas de José Pedroso e Jan Zach e mobiliário de Joaquim Tenreiro.

Peixoto é considerado o mentor da arquitetura moderna em Cataguases. Participante ativo das atividades do grupo dos Verdes nos anos 1920, o industrial foi um dos principais financiadores desse processo de "renovação" na cidade. Como destaca Iphan (1994, p. 06):

O mecenato surge como elemento decisivo na produção e na difusão de bens culturais, encarnado na figura de empresários de perfil tão modernista quanto os artistas que apoiaram. Não se tem notícia da injeção de recursos públicos na formação do mais importante polo de modernidade em Minas Gerais. Foi a iniciativa privada local que promoveu 
a invasão de Cataguases pela arquitetura, pelas artes plásticas e pelo design com as características de modernidade que até hoje identificam $e$ orgulham a cidade.

Em 1943, o industrial encomenda a Niemeyer o projeto do Colégio Cataguases (Figura 1) para a substituição do antigo edifício que $\mathrm{o}$ abrigava. $\mathrm{O}$ colégio possui paisagismo de Burle Marx, escultura de Jan Zach, painel em pastilha de Paulo Werneck e mobiliário de Joaquim Tenreiro, além de ter abrigado em seu saguão principal o painel de Cândido Portinari, Tiradentes, hoje acervo do Memorial da América Latina em São Paulo.

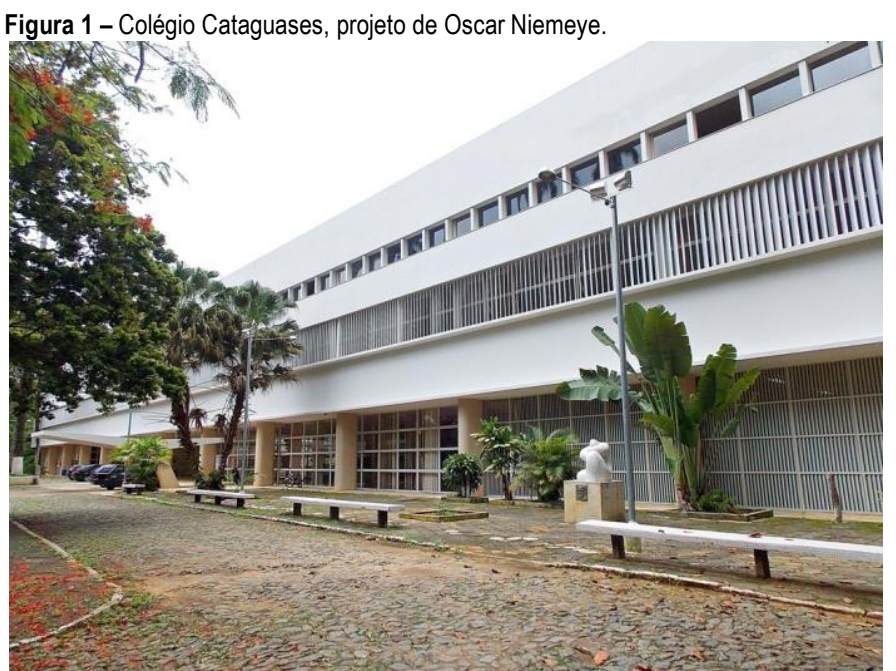

Fonte: PEREIRA, 2015, p. 151

A partir desses dois projetos, seguiu-se a execução de inúmeros outros, de uso público e privado, que a elite cataguasense encomendou a arquitetos modernistas que atuavam no Rio de Janeiro.

Tendo em vista essa produção arquitetônica, se elaborou um dossiê de tombamento embasado pela seguinte premissa:

No plano conceitual é mister situar o debate, orientando-se no sentido da superação da dicotomia entre as obras tidas e havidas de excepcional valor, expressões máximas e acabadas dos novos enunciados estéticos, emblemáticos e um novo período artístico ou revelador de notáveis qualidades de seus criadores e aquelas que apenas denotam os padrões correntes, diluídos nas paisagens rotineiras do cotidiano urbano [...]. (IPHAN, 1994, p. 49)

Contudo, ao eleger 16 bens para o tombamento isolado, o documento, ao invés de superar tal dicotomia, a acentuou.
Cataguases não se conforma como um conjunto homogêneo, como as cidades patrimônio até então protegidas no estado, pois as edificações e as obras modernistas estão dispersas pela cidade, mescladas a outras tipologias, como o neocolonial, art decó, eclético e arquitetura industrial. Tal realidade urbana representou aos técnicos do Iphan um desafio, pois ao se reconhecer as obras modernistas consideradas de valor significativo, poderia se incorrer no risco de não reconhecer toda a importância do processo histórico, cultural, social e econômico produzidos em Cataguases. Assim, considerou-se que:

[...] a melhor forma de se promover o
reconhecimento e a proteção do patrimônio
cultural da cidade é constituí-lo enquanto parte
integrante do centro urbano; a ausência de unidade
enfatiza uma das principais características do
movimento modernista em Cataguases, qual seja o
seu caráter inconcluso. As contradições e conflitos
decorrentes do tratamento do conjunto
representam ademais fator relevante para o
entendimento dos processos identificados com os
exitos e malogros dos rumos imprimidos à
renovação da cidade e à ação dos "modernistas".
(IPHAN, 1994, p. 51)

Para tanto, o documento enfatizou a necessidade de discutir um novo conceito de Centro Histórico, onde Cataguases:

[...] revela a complexidade de sua história em um novo conceito de Centro Histórico, considerandose, sobretudo, seus períodos mais recentes. Conceito que rompe os limites impostos pelo peso da herança adquirida irrefletidamente da cultura europeia, acostumada a circunscrever os interesses prioritários aos remanescentes da sociedade préindustrial cujo ideal de harmonia sempre estimulou os sentimentos de admiração e respeito. (IPHAN, 1994, p. 52)

Desta forma, além dos bens tombados isoladamente - dos quais onze são modernistas e cinco anteriores a estes estabeleceu-se o perímetro que definiu a área de interesse cultural (Figura 2).

Não obstante, já prevendo as dificuldades de preservação, o documento apontou que as diretrizes de gestão deveriam ser diferentes das adotadas nas outras cidades-patrimônio mineiras, ficando os bens inventariados sob tutela do Iphan, assim como o traçado urbano. Já os demais imóveis que compõem o centro histórico deveriam ficar submetidos às posturas municipais. 


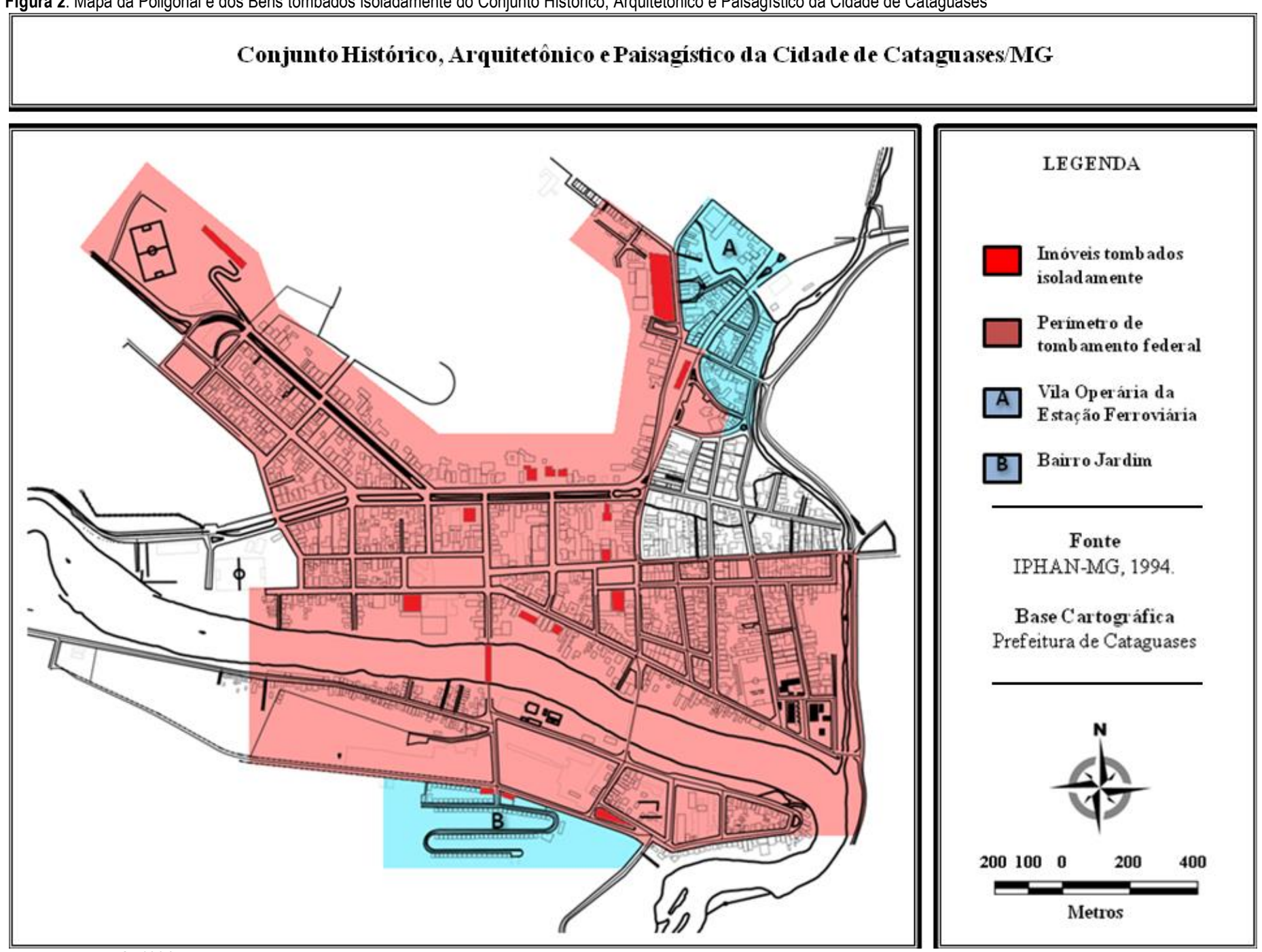

O processo de tombamento apontou ainda a necessidade da realização de novos inventários dentro do perímetro de proteção para listar outros imóveis relacionados à formação e desenvolvimento da cidade, contudo entendese que tais inventários deveriam ter sido realizados durante a instrução do processo, de preferência com a participação da comunidade, para que os mesmos pudessem ter sido apreciados pelo Conselho Consultivo do Patrimônio do Iphan. Corrobora com essa afirmação o fato de que tais inventários nunca foram elaborados, fazendo com que a inscrição do bem tombado em 1994 só ocorresse em 2003 nos Livros do Tombo de Belas Artes, Histórico e Arqueológico, Etnográfico e Paisagístico.

Dentre as consequências da não realização de tais inventários, houve a exclusão do acervo móvel (mobiliário), uma vez que não era possível precisar no que se referiam tais bens, assim, ficou tombado:

O Conjunto Histórico, Arquitetônico e Paisagístico da Cidade de Cataguases, no Estado de Minas Gerais, de acordo com o perímetro delimitado nos autos, observando a condição de especial destaque conferida aos bens imóveis e integrada relacionada, assim como a exclusão do acervo móvel. (IPHAN, 2003, p.01, grifo nosso)

Quanto às posturas municipais, em 2006 elaborou-se um Plano Diretor Participativo (PDP), exigido pelo Estatuto da Cidade. Com recursos do Programa Monumenta, um dos eixos abordados deveria ter sido a preservação do patrimônio cultural, contudo, esse tema não foi levantado em nenhuma das reuniões com a comunidade durante sua elaboração, fato que mostra como a questão da preservação se mostrava distante da comunidade.

Por iniciativas de técnicos municipais, foi sugerido na criação do anteprojeto o estabelecimento de uma Zona de Preservação Cultural que, além da poligonal de tombamento do Iphan, reconhecia o interesse cultural de outras áreas adjacentes. A Zona teria uma permeabilidade mínima de $30 \%$ e limite de gabarito de no máximo nove metros para as novas edificações, assim se garantiria a manutenção da paisagem do conjunto urbano tombado 
que, segundo Alonso (2013), vem sofrendo forte pressão do setor imobiliário por verticalização, o que além do prejuízo paisagístico, acarretaria um desconforto ambiental por prejudicar a circulação dos ventos e propiciaria a formação de ilhas de calor (informação verbal $)^{3}$.

Contudo, quando a lei já aprovada pela Câmara Municipal retornou ao Executivo para ser sancionada, o Prefeito Municipal vetou os incisos que tratavam da permeabilidade e do gabarito da Zona de Proteção Cultural. Para Alonso (2013), tais vetos estão relacionados a pressões por parte de alguns setores da construção civil que atuam no município (informação verbal) ${ }^{4}$.

Desta forma, percebe-se o quão complexo é a gestão do patrimônio em Cataguases, de um lado por parte da municipalidade e de outro pelo próprio Iphan que, por não ter normas e critérios estabelecidos, e nem ter realizado os inventários sugeridos no processo de tombamento, tem dado margens a ações de grupos influentes contrários à preservação. Conforme Alonso (2010, p. 96):

$O$ detalhamento das coisas individualmente que ao ser somado daria escopo ao conjunto não há. Não há inventário. Não há no processo os critérios e a justificativa técnica da escolha dos suportes - bens tombados individualmente e delimitação do perímetro - que representariam as manifestações culturais de Cataguases.

Logo, constatou-se que, mesmo protegido juridicamente, sem a realização dos inventários capazes de detalhar o complexo e rico patrimônio da cidade de Cataguases dotando-o de normativas claras e eficientes de gestão, tendo o poder público e a comunidade local como parceiros -, a sua salvaguarda não está garantida.

\section{Entre a reificação da arquitetura modernista e 0 apagamento da memória industrial}

O Dossiê de Tombamento de Cataguases traz em sua apresentação uma noção ampliada de patrimônio cultural, afinada com as reflexões realizadas durante os anos 1970 e 1980 e com a definição de patrimônio cultural apresentada na Constituição de 1988, como podem ser observadas:

Este fim de século mostra a saturação de certas práticas e certas teorias e nos empurra para a busca de alternativas aptas a acercarem-se da identificação, documentação, proteção e promoção do patrimônio cultural, em sua pluralidade. Se antes as políticas públicas privilegiavam os monumentos barrocos e a homogeneidade dos conjuntos arquitetônicos setecentistas, agora são as cidades e as diferenças que o espaço urbano concentra que estão no centro da cena. $O$ patrimônio cultural é hoje composto, construído e tecido na vida cotidiana de todas as cidades, não apenas daquelas chamadas históricas, pois afinal a história de Minas não parou no século XVIII, nem a história do Brasil começou com a chegada dos portugueses. Agora que a orientação linear da História encontra-se sob relativa suspeição, a ocupação do território, com seus diferentes modos de criar, fazer e viver exigiu a superação da clássica distinção entre cultura e natureza. (IPHAN, 1994, p. 05)

$\mathrm{O}$ documento traz ainda diversas citações que dizem respeito à memória, onde destaca-se a seguinte passagem:

Toda dificuldade se encontra em considerar a memória construída em termos de movimento, conflito e imprevisibilidade [...]. À medida que aspectos sociais são considerados os conceitos de memória se diversificam: memória social, atos coletivos de lembrar e esquecer, tradição [...]. (SANTOS, 1993 apud IPHAN, 1994, p. 19)

Contudo, cabe o questionamento de que se a noção ampliada de patrimônio e de memória balizaram os estudos para o tombamento da cidade-patrimônio de Cataguases, por que o conjunto protegido ali não reflete tais discussões? $\mathrm{O}$ documento demonstra uma preocupação em garantir a salvaguarda das várias manifestações culturais da cidade ao se embasar nas manifestações culturais, sociais e econômicas de Cataguases - a morfologia inicial do arraial, a economia cafeeira, a importância da ferrovia para o desenvolvimento econômico, social e urbano, a chegada de imigrantes, as edificações neocoloniais, ecléticas, art decó, modernistas, o processo de industrialização, a classe operária e suas vilas, a literatura com os Verdes, o ciclo do cinema de Humberto Mauro, Pedro Camello e Eva Nill. Desta forma, o que parecia ambicioso e sem dúvida traria importantes contribuições para as políticas de preservação do patrimônio no Brasil, o tombamento não conseguiu efetivar.

No que se refere à produção arquitetônica modernista, como já foi mencionado, tem-se uma expressiva produção de artistas residentes no Rio de Janeiro na década de 1940, como Niemeyer, Bolonha, Portinari, Burle Marx, entre outros. Na década seguinte surgem obras do arquiteto Luzimar Goés Telles, morador da cidade e que teve uma produção, segundo Alonso (2010, p. 87), que "se destaca pela quantidade e variedade dos programas arquitetônicos", sendo o arquiteto que mais produziu obras modernistas em Cataguases, que vão desde industrias e seus respectivos escritórios, reformulação de praças, sindicatos, clubes, fórum, hospitais, consultórios médicos, blocos residenciais, residências, entre tantos outros projetos. Contudo, mesmo o dossiê reconhecendo a importância do legado de Telles, autor de cerca de sessenta 
projetos realizados em Cataguases, o arquiteto não teve nenhum exemplar eleito para tombamento individual.

Outra ausência marcante entre os bens listados para o tombamento isolado foi a da Igreja Matriz Santa Rita de Cássia (Figura 3), o projeto de Edgar Guimarães do Valle com mural externo em azulejos de Djanira e pinturas parietais internas de Nanzito Salgado, segundo pesquisas realizadas em 2006 para a elaboração do PDP com a população local para identificar quais seriam as edificações mais representativas de Cataguases, foi apontada como o principal sustentáculo de identidade da comunidade, como pode se observar:

Em relação à arquitetura temos a quase unanimidade na avaliação popular em relação à Igreja de Santa Rita, com 93,3\% de respostas válidas para os quesitos "importante" e "muito importante”; seguida pelo Colégio Cataguases, com $90,9 \%$ e a Chácara Catarina, com 84,4\%. Aqui, a grande distinção encontra-se no conhecimento amplo destes monumentos pela comunidade, o que os tornam amplamente populares. (UFMG, 2006 apud ALONSO, 2010, p. $84)^{6}$

Desta forma, para um documento que aparentemente pretendia salvaguardar uma significativa variedade de manifestações culturais, no âmbito da arquitetura as escolhas já se mostraram bem restritas. Ao selecionar dezesseis bens para o tombamento individual, o processo já criou uma hierarquia simbólica dos bens que compõem o conjunto, que associado ao fato de que os bens filiados à tradição modernistas são todos criações de arquitetos e artistas renomados que possuem obras dispersas pelo Brasil e pelo mundo, permite afirmar que a memória que se salvaguardou foi, em primeiro lugar, de um grupo específico de arquitetos e artistas, os mesmos que historicamente o Iphan reverenciou, e, por outro lado, da elite de Cataguases, que financiou essa produção arquitetônica, práticas das mais arraigadas, tradicionalistas e anacrónicas do instituto federal.

Além disso, a eleição desses bens no plano do vivido significou a valoração de um processo de renovação urbana que substituiu alguns dos principais espaços públicos da cidade, espaços com os quais certamente a população local mantinha laços de identidade, por imóveis até então estranhos naquela cidade, apenas para saciar desejos pessoais das elites locais.

Não obstante, o Dossiê de Tombamento de Cataguases foi conivente com a substituição desses lugares das lembranças do viver e da vida cotidiana, legitimando a reificação da técnica e da arquitetura em detrimento da memória, em particular da memória das camadas sociais populares.

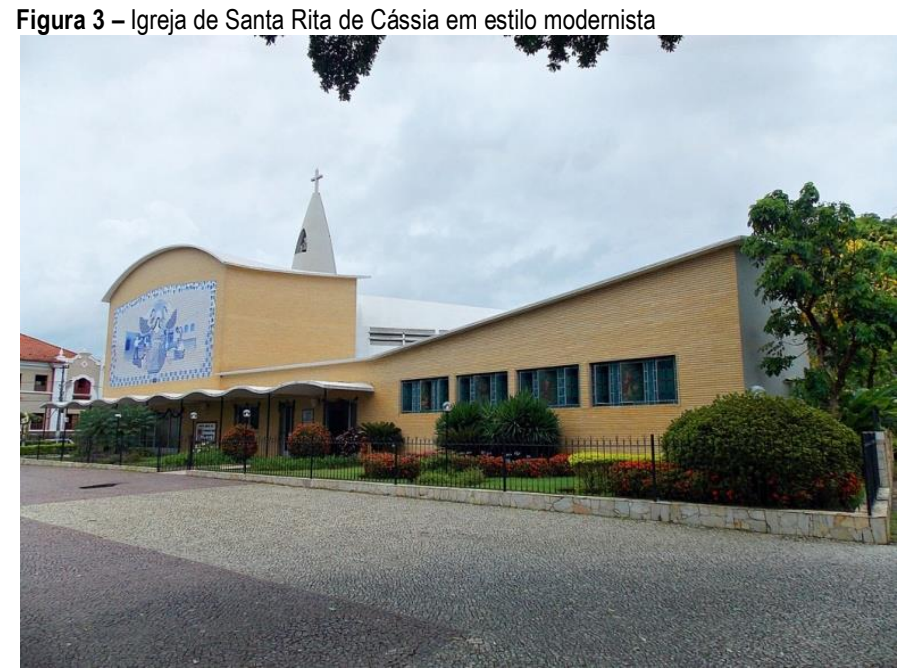

Fonte: PEREIRA, 2015, p.149

Figura 4 - Igreja Matriz de Santa Rita de Cássia na década de 1940

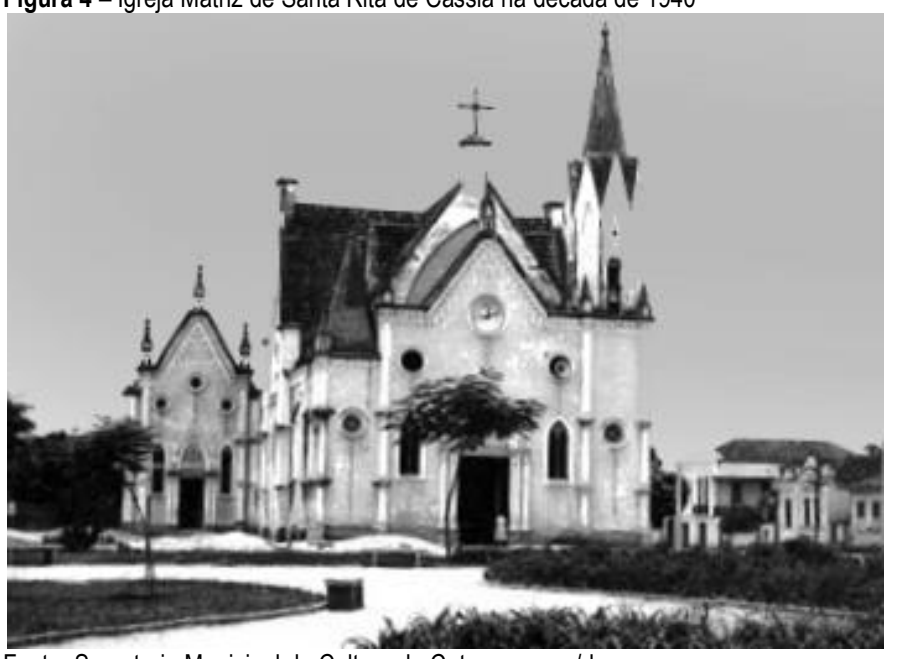

Fonte: Secretaria Municipal de Cultura de Cataguases, s/d

Nesta perspectiva, vale citar a substituição da Igreja Matriz de Santa Rita, construída em 1894 em arquitetura neogótica (Figuras 4), e do Cine-Teatro Recreio de 1893, em arquitetura maneirista italiano, que, ao lado do Paço Municipal, da Fábrica Irmãos Peixoto, da Chácara Dona Catarina e do Hotel Villas, representavam o primeiro ciclo de expansão econômica da cidade, com a chegada da ferrovia no final do século XIX e início do XX, momento em que Cataguases se constituía como uma ilha de desenvolvimento envolvida por grandes áreas de cultivo de café. A Igreja e o Cine-Tetro foram, respectivamente, substituídos em 1944 e 1946, ou seja, ambos com cerca de 50 anos de história.

No que se refere aos bens tombados individualmente de períodos anteriores ao modernismo, estes têm uma forte ligação com o ciclo da cafeicultura e com o processo de industrialização que marcou a história de Cataguases. O palacete onde hoje funciona o Museu da Eletricidade Cataguases-Leopoldina e o edifício do Grupo Escolar Coronel Vieira são exemplares ricos do auge da cafeicultura na Zona da Mata mineira. Já a Estação 
Ferroviária representa a chegada da modernidade, que possibilitou a industrialização, processo representado pela Indústria Irmão Peixoto e pela Ponte Metálica, essa última possibilitou a ocupação da outra margem do rio pela expansão da atividade industrial.

Aqui cabe uma observação, além da arquitetura modernista, no processo de tombamento do Conjunto Histórico, Arquitetônico e Paisagístico de Cataguases perdeu-se a oportunidade de valorar outro importante elemento fortemente marcante do conjunto da cidade, e que poderia lhe conferir destaque em relação a outras cidades-patrimônio, visto que estas são formas de produção do espaço historicamente desvalorizadas, o patrimônio industrial.

Cataguases possui um expressivo patrimônio industrial formado por indústrias, vilas operárias, sindicatos e o conjunto ferroviário, contudo, o tombamento federal não garante a proteção desse rico conjunto que, sem o respaldo das políticas públicas de patrimônio, está em franco processo de desaparecimento, em particular as residências das vilas que passaram a ser vendidas individualmente pelas empresas, como também já destacou Alonso (2010).

Nesta perspectiva, antes de proceder a análise destes lugares marcados pela atividade industrial, e tendo em vista que o Dossiê de Tombamento de Cataguases teve na discussão de memória uma de suas sustentações de valoração como já mencionamos, entende-se que cabe a reflexão acerca dos lugares de memória operária. Conforme Scifoni (2013a, p. 103), sua compreensão:

[...] envolve pensar na ordem local, como dimensão na qual se criam os laços de identidade e de solidariedade, o plano em que se dá a vida cotidiana marcada pelo ritmo da fábrica e pelas lutas e resistência ao processo de alienação no trabalho, atravessadas, contraditoriamente, pelas contingências da ordem distante, do mundial [...]. Neste sentido, as categorias de lugares de memória operária representam as diferentes formas como essas experiências coletivas e de classe se inscrevem nos espaços concretos.

Em Cataguases, as experiências coletivas da classe operária inscritas no espaço que se destacam são, basicamente, os lugares de memória do trabalho e os de moradia. Para a autora o primeiro se define:

[...] pelas fábricas ou pelos eixos viários ao longo dos quais estas se concentraram, conformando espaços da industrialização. A fábrica revela-se como organizadora da vida social e como referência espacial, pois que regula o movimento do bairro, a circulação nas ruas próximas. Nela se inscreve a memória operária não só como lembrança da atividade profissional e das condições do trabalho parcelar e repetitivo que aliena, mas como recordação de uma sociabilidade regulada pelo tempo do relógio e do apito da fábrica e pela necessidade de organização e luta. (SCIFONI, 2013a, p. 105)

Ao eleger para tombamento individual a Indústria Irmãos Peixoto e ao incluir na poligonal de tombamento a Companhia Industrial de Cataguases, as duas principais indústrias na formação histórica e cultural da cidade, se garante a salvaguarda da materialidade dos lugares de memória do trabalho, mesmo que o uso da primeira já tenha mudado, hoje se constituindo como um shopping popular.

Já os lugares de moradia operária, para Scifoni (2013, p. 104) representam:

\section{[...] as experiências compartilhadas do viver operário, com seus limites e possibilidades. Incluem-se projetos que surgiram de forma pioneira como alternativa coletiva, frente às precárias condições de vida e que tornaram os operários sujeitos na produção do espaço da cidade. Lugares que expressam, também, a intenção de controle e sujeição total do trabalhador ao Capital e ao Estado e as consequentes formas de resistências à imposição do espaço abstrato.}

Esses lugares de morar, que em Cataguases já foram sete vilas, estão desaparecendo, e mesmo com todos os problemas de gestão que esta cidade patrimônio apresenta, como já citado, os modos de morar operário nem foram incluídos na poligonal de tombamento, com exceção da Vila Operária Irmãos Peixoto, que se constitui como uma extensão espacial da Fábrica.

Contudo, na primeira área de expansão da cidade determinada pelo traçado da linha férrea, onde se encontra a Estação, uma importante área que possibilitaria concatenar esse momento histórico da cidade ficou fora do perímetro de tombamento. Trata-se da Vila Operária da Estação Ferroviária, onde ficavam as moradias dos funcionários da ferrovia e várias edificações que mantinham relação com a estação, como armazéns (área A destacada no mapa da Figura 2).

O mesmo ocorreu onde se encontram as instalações da Companhia Industrial de Cataguases. No entanto, neste caso a reificação da arquitetura em detrimento da memória do trabalho é explícita. A linha que delimita a poligonal de tombamento passa dentro do Bairro Jardim (Figuras 5 e 6), vila operária da Companhia Industrial, contudo, somente foram incluídas as edificações projetadas por Francisco Bolonha - bens que foram tombados individualmente não incluindo as outras cem moradias dispostas na encosta construídas antes da obra de Bolonha (área A destacada no mapa da Figura 2). 


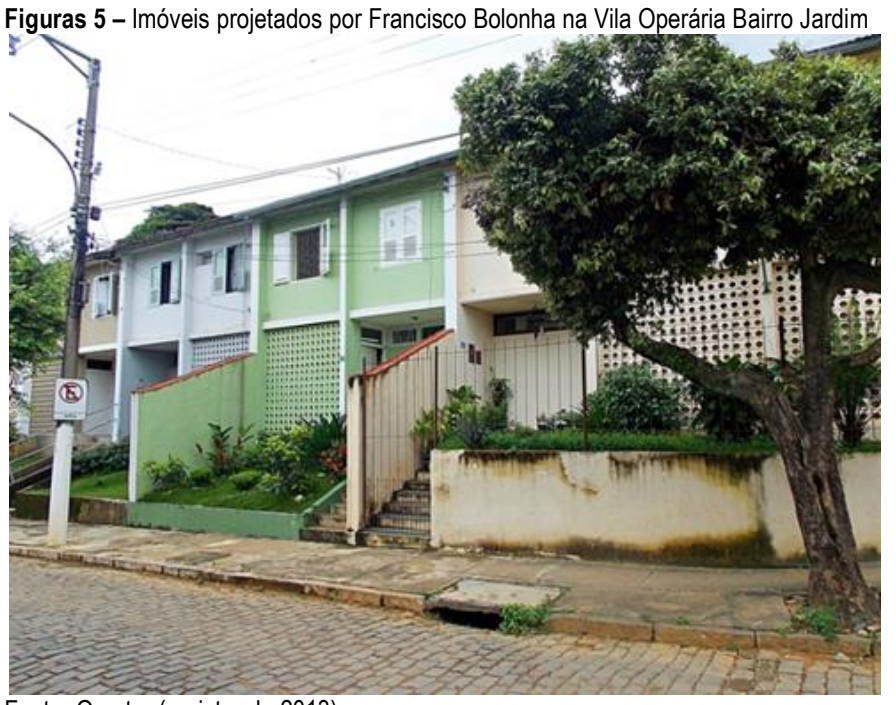

Fonte: $O$ autor (registro de 2013)

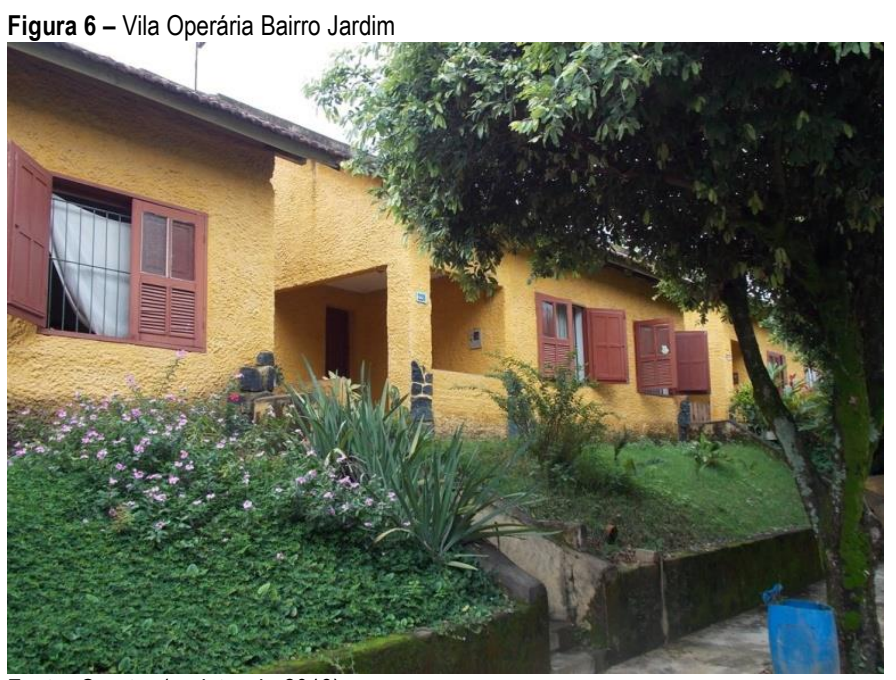

Fonte: 0 autor (registro de 2013)

De acordo com Alonso (2010, p. 89):

O Bairro Jardim chama a atenção pela sua implantação: ruas quase que paralelas às curvas de nível; moradias implantadas no meio do terreno com afastamentos nas quatro faces; cortes cuidadosos nos terrenos de forma a evitar deslizamentos de terra; jardins frontais nas residências sem fechamentos por muros ou gradis [...]. Esta morfologia confere a essa vila operária condições bastante favoráveis de conforto ambiental, principalmente, no que diz respeito à ventilação e sombreamento, numa cidade onde os níveis de temperatura e umidade são razoavelmente desconfortáveis [...]. Este tipo de implantação seria, a nosso ver, inclusive um exemplo a ser seguido nas demais ocupações de encostas no restante da cidade.

Portanto, considera-se que os bens culturais reconhecidos pelo Estado em Cataguases hoje representam a memória da elite em detrimento das classes sociais populares, em particular a dos trabalhadores. A arquitetura modernista eleita é a vinculada aos arquitetos do Rio de Janeiro, que foi construída para satisfazer os anseios da elite industrial local, acarretando a demolição de importantes sustentáculos de identidade coletiva cataguasense.

\section{Considerações Finais}

É importante salientar que não se objetivou aqui diminuir a importância da arquitetura modernista de Cataguases, uma vez que essa se constituiu em um dos mais importantes exemplares de conjunto em arquitetura modernista do Brasil ${ }^{7}$, mas entende-se que seja necessário reconhecer que, além de modernista, Cataguases é uma cidade moderna, uma vez que a arquitetura neocolonial, a eclética, a art decó e a industrial são vertentes diferentes do movimento moderno, e que o modo de vida pautado pelo tempo do relógio e pelo apito da fábrica são os maiores símbolos da modernidade, o que de fato justificaria o título de "Patrimônio da Modernidade" da cidade.

É importante destacar também, que as contradições presentes do processo de tombamento da cidadepatrimônio de Cataguases refletem um momento de transição e de disputas internas no Iphan, quando diferentes grupos de técnicos se articulavam para terem suas concepções de patrimônio dominantes em um dos momentos de maior crise da instituição, quando tanto o instituto quanto o Ministério da Cultura foram extintos pelo governo Collor.

Por fim, para garantir a preservação desse importante patrimônio do Brasil, é necessário que se retome os projetos participativos iniciados em 1987, com a aproximação do Iphan, da prefeitura e da comunidade, para que juntos elaborem os inventários solicitados à época do tombamento, que seja revisto o perímetro de tombamento e se estabeleçam as normativas para guiar as intervenções dentro do perímetro de tombamento.

\section{Agradecimentos}

Este texto é parte dos resultados da dissertação intitulada "Cidades patrimônio: uma geografia das políticas públicas de preservação no Brasil" apresentada ao Programa de Pós-graduação em Geografia Humana da Universidade de São Paulo (FFLCH/USP). Agradeço a Prof $^{a}$ Dr $^{a}$ Simone Scifoni por ter orientado essa pesquisa e à Fundação de Amparo à Pesquisa do Estado de São Paulo (FAPESP) pelo seu financiamento. Seus apoios foram imprescindíveis para o desenvolvimento deste trabalho. 


\section{Notas}

(1) Durante os seus 79 anos de existência, o órgão federal de preservação possuiu várias designações, o que mostrava o seu lugar na estrutura política de governo. Foi criado como SPHAN (Serviço de Patrimônio Histórico e Artístico Nacional) em 1937, assumindo a sigla de DPHAN (Departamento de Patrimônio Histórico e Artístico Nacional) em 1946, IPHAN em 1970, voltando a ser SPHAN em 1979, IBPC (Instituto Brasileiro de Patrimônio Cultural) em 1990 e, por fim, novamente IPHAN em 1995. Contudo, por preferência, o órgão de preservação do patrimônio cultural federal será referido sempre como Iphan.

(2) Informação fornecida por Márcia Chuva, historiadora do Iphan entre 1985 e 2009, em entrevista ao autor (Rio de Janeiro, setembro de 2013).

(3) Informações concedidas por Paulo Henrique Alonso, presidente do Instituto Cidade de Cataguases, em entrevista ao autor (Cataguases, dezembro de 2013).

(4) Ibid.

(5) SANTOS, M. O passado da amnésia coletiva: um estudo sobre os conceitos da memória, tradição e traços do passado. Revista Brasileira de Ciências Sociais. São Paulo: ANDOCS, n. 23, 1993.

(6) Escola de Arquitetura da Universidade Federal de Minas Gerais, 2006.

(7) O primeiro bem modernista tombado pelo Iphan foi a Igreja de São Francisco de Assis (MG) em 1947, seguido pelo tombamento de dezenas de bens isolados no país. A primeiro conjunto urbano modernista só foi tombada em 1990, Brasília (DF), seguido por Cataguases (MG) e pela Lagoa da Pampulha (MG) em 1994, e pala Vila de Serra do Navio (AP) em 2012, completando o quadro de conjuntos urbanos modernistas tombadas em nível federal.

\section{Referências}

ALONSO, P. H. A construção de um patrimônio cultural: o tombamento federal de Cataguases, Minas Gerais. $2010.201 \mathrm{f}$. Dissertação (Mestrado em Gestão do Patrimônio em Ambiente Construído) - Faculdade de Arquitetura e Urbanismo, Universidade Federal de Minas Gerais, Belo Horizonte, 2010.

. Guia da Arquitetura Modernista de Cataguases. Cataguases: Instituto Cidade de Cataguases, 2012.

BRASIL. Decreto-Lei no 22.928 de 12 de junho de 1933. Erige a cidade de Ouro Preto em monumento nacional. Diário Oficial da União. Rio de Janeiro, DF, jul. 1933.

Decreto-Lei no 25 de 30 de novembro de 1937. Organiza a proteção do patrimônio histórico e artístico nacional. Diário Oficial da União. Rio de Janeiro, DF, nov. 1937.

FONSECA, M. C. L. O patrimônio em processo: trajetória da política federal de preservação no Brasil. Rio de Janeiro: UFRJ/Iphan, 2009.

IPHAN. Dossiê de Tombamento - Cataguases. Belo Horizonte: Iphan/MinC, 1994.

Anexos - Processo de tombamento de Cataguases. Rio de Janeiro: Iphan/MinC, 2003.

MOTTA, L. Patrimônio Urbano e Memória Social: práticas discursivas e seletivas de preservação cultural - 1975 a 1990. 2000. 173f. Dissertação (Mestrado em Memória Social e Documento) - Centro de Ciências Humanas, Universidade Federal do Estado do Rio de Janeiro, Rio de Janeiro.

PEREIRA, D.C. Cidades patrimônio: uma geografia das políticas públicas de preservação no Brasil. 2015. 188f. Dissertação (Mestrado em Geografia Humana) - Faculdade de Filosofia, Letras e Ciências Humanas, Universidade de São Paulo, São Paulo.

SANT’ANNA, M. Da cidade-monumento à cidade-documento: a trajetória da norma de preservação de áreas urbanas no Brasil (1937-1990). 1995. 283f. Dissertação (Mestrado em Arquitetura e Urbanismo) - Faculdade de Arquitetura e Urbanismo, Universidade Federal da Bahia, Salvador.

SCIFONI, Simone. LUGARES DE MEMÓRIA OPERÁRIA NA METRÓPOLE PAULISTA. GEOUSP: Espaço e Tempo (Online), São Paulo, n. 33, p. 98-110, apr. 2013. ISSN 2179-0892. Disponível em: <http://www.revistas.usp.br/geousp/article/view/74304>. Acesso em: 09 aug. 2016. doi::http://dx.doi.org/10.11606/issn.21790892.geousp.2013.74304. 
Para além do capital: o patrimônio industrial na perspectiva dos trabalhadores. In: Anais do VI Encontro Internacional Arquimemória. Salvador: IAB, 2013b, p. 1-17.

\section{${ }^{1}$ Danilo Celso Pereira}

Geógrafo. Mestre em Geografia Humana. Endereço postal: SEP 713/913, Bloco D, $3^{\circ}$ andar, Brasília, DF, Brasil, CEP 70398-135 